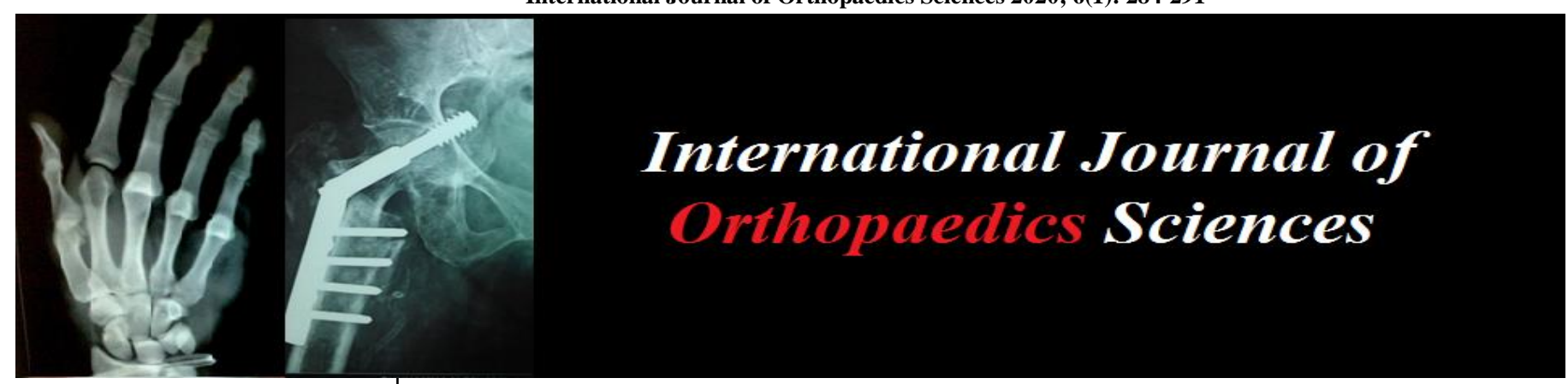

E-ISSN: 2395-1958

P-ISSN: 2706-6630

IJOS 2020; 6(1): 284-291

(C) 2020 IJOS

www.orthopaper.com

Received: 23-11-2019

Accepted: 27-12-2019

Dr. Debabrata Som

Ex Junior Resident

Orthopaedics, DNB, Malla

Reddy Institute Of Medical

Sciences, Hyderabad, Telangana, India

Dr. Karthikeyan Dhandapani Junior resident Orthopaedics, DNB, Malla Reddy Institute of Medical Sciences, Hyderabad,

Telangana, India
Corresponding Author:

Dr. Debabrata Som

Ex Junior Resident

Orthopaedics, DNB, Malla

Reddy Institute Of Medical

Sciences, Hyderabad, Telangana,

India

\section{A study of different surgical modalities in the management of proximal humerus fractures}

\section{Dr. Debabrata Som and Dr. Karthikeyan Dhandapani}

DOI: https://doi.org/10.22271/ortho.2020.v6.i1e.1875

\section{Abstract}

Background: Proximal humerus fractures are common but debilitating injuries. Numerous factors contribute to post injury functional outcomes; therefore, a large debate exists over appropriate treatment. Optimal treatment for displaced or unstable two, three, and four-part proximal humerus fractures remains controversial. This study is conducted to analyze the results of proximal humerus fractures treated by different modalities of surgical fixation.

Materials \& Methods: This study was carried out in Malla Reddy Institute of Medical Sciences, from July 2016 to June 2018. Thirty patients of displaced proximal humeral fractures were admitted in this hospital and treated surgically by PHILOS plate, K-wire and hemiarthroplasty. Follow up is done from 4 weeks to 12 months both clinically and radiologically. Results were evaluated by the use of Neer's shoulder score.

Results: Most common mode of injury was found to be road traffic accident and the most common type was two part fracture accounting for 12 out of 30 patients $(40 \%)$. The results were evaluated by Neer's score. The average follow up duration was 11.4 months. Of the thirty patients, $7(23.3 \%)$ had excellent results, $17(56.7 \%)$ had satisfactory results, $4(13.3 \%)$ had unsatisfactory results and $2(6.67 \%)$ were failure.

Conclusions: Closed reduction and percutaneous pinning can be used for un-displaced or displaced fractures of the proximal humerus without comminution, in the younger age groups with good bone quality. In older individuals it is good to fix with percutaneous $\mathrm{K}$ wires, considering bone density (osteoporosis) and also to reduce the period of surgery. $\mathrm{K}$ wire fixation gave excellent results in our patients for the treatment of unstable 2 part proximal humerus fractures. Proximal humerus locking plate (PHILOS) gives reliable fixation for 2-part and 3-part fractures and has good functional outcome. In more complicated fracture patterns of 4-part fractures, its use is associated with poor clinical outcome. Prosthetic replacement should be considered as primary treatment in cases with marked comminution of the humeral head, in fracture-dislocations, and in elderly patients.

Keywords: PHILOS plate, hemiarthroplasty, Neer's score, proximal humerus fractures, surgical management

\section{Introduction}

Proximal humerus fractures are common but debilitating injuries, which result in significant morbidity for the patient and both diagnostic and treatment challenges for the surgeon. Fractures of proximal humerus are not uncommon, especially in older age group. They have been reported to account for $4 \%-5 \%$ of all fractures ${ }^{[1]}$. These are the second most common upper-extremity fractures and the third most common fractures, after hip and distal radial fractures. About $85 \%$ of these fractures are minimally displaced or non-displaced and are effectively treated symptomatically with immobilization followed by early motion. The remaining $15 \%$ of fractures are displaced unstable and provide a therapeutic challenge ${ }^{[1]}$.

The vast majority are low energy fractures occurring in elderly individuals with more high energy and complex fractures in younger patients happening less frequently ${ }^{[2-3]}$. The incidence tends to increase with age, and elderly individuals who sustain these fractures are more commonly female, over the age of 60 years. These patients often have osteoporosis ${ }^{[4]}$.

Nearly $75 \%$ of proximal humerus fractures occur in patients older than 60 yrs who have fallen from a standing height ${ }^{[2,5]}$. The majority of proximal humerus fractures in this age group are relatively non-displaced and can be treated successfully without surgery ${ }^{[6]}$. 
Risk factors for proximal humerus fractures include elderly patients, low bone mineral density, impaired vision and balance, absence of hormone replacement therapy, smoking, more than three chronic illnesses, and previous fragility fracture ${ }^{[2,7]}$.

Younger patients sustain proximal humerus fractures as a result of motor vehicle accidents, seizures, electric shock, and fall from greater than a standing height ${ }^{8}$. These injuries tend to involve more significant bony and soft tissue disruption and accordingly are treated with surgical intervention ${ }^{[5]}$.

Current therapeutic options for proximal humerus fractures are IM nails, plates, tension band wiring, and percutaneous (or) minimally invasive technique such as pinning, intramedullary flexible nails, screw osteosynthesis and hemiarthoplasty.

Nonoperative versus operative management of these injuries depends on the mechanism of injury, the patient's physiologic age, including activity level, and fracture pattern ${ }^{[3]}$.

Management of these fractures is associated with some morbidity and undesirable sequelae. They include complication like avascular necrosis, malunion, non-union, infection, neurovascular injury, loss of motion of shoulder from adhesive capsulitis, chronic edema, elbow stiffness and atrophy of the soft tissues of the immobilized limb causing significant disability during healing and afterwards.

Regardless of the age of the patient or mechanism of injury, restoration of pain-free functional range of motion remains the primary treatment goal of these injuries.

Numerous factors contribute to post injury functional outcomes; therefore, a large debate exists over appropriate treatment ${ }^{[9]}$. Optimal treatment for displaced or unstable two, three, and four-part proximal humerus fractures remains controversial.

This study is conducted to analyze the results of proximal humerus fractures treated by different modalities of surgical fixation.

\section{Aim and Objectives}

Aim: To study different surgical modalities in the management of proximal humerus fractures.

\section{Objectives}

1. To study the occurrence, mechanism of injury and displacement of various types of fracture according to Neer's classification.

2. To study the following different modalities of surgical fixations in proximal humerus fractures:

- Open reduction and internal fixation with PHILOS Plate

- Open reduction/closed reduction and internal fixation with K-Wires

- Hemiarthroplasty

3. To assess the functional outcome.

4. To evaluate fracture union and complications.

5. To draw conclusions about preferred modality of treatment of proximal humerus fractures.

\section{Materials and methods}

This study was carried out in Malla Reddy Institute of Medical Sciences, from July 2016 to June 2018 after getting ethical clearance from the hospital. Thirty patients of proximal humeral fractures were attended to in the casualty and OPD and were admitted in this hospital and treated surgically. Informed consent was obtained from all the patients included in the study.
We collected records of the patients by asking the patients history and examining the patients. Essential investigations of all the patients were done. The patients were operated with various modalities of fixation. Patients were followed up at regular intervals.

\section{Inclusion Criteria}

1. Age $>18$ yrs of both sexes

2. Failure of closed reduction in two part fractures

3. All displaced three and four part fractures

4. Fracture dislocations

\section{Exclusion criteria}

1. Fractures in children

2. Pathological fractures

3. Patients with distal neurovascular deficit

4. Polytrauma patients with an Injury Severity Score $>16$

5. Shaft humerus fractures with proximal extension

6. Patients not willing for study

\section{Method of Treatment}

All the patients were operated on either elective or emergency basis depending on whether fracture is closed or open. All patients were treated by one of the following methods.

1. Closed/open reduction with $\mathrm{K}$ - wire fixation.

2. Open reduction and Internal fixation with PHILOS Plate.

3. Shoulder Hemiarthroplasty with NEER's prosthesis.

\section{Post-operative care}

Post-operatively limb is immobilized in arm pouch, sutures were then removed and if secure fixation was achieved, mobilization was started in the second week beginning with pendulum exercices and progressing to shoulder wheel exercises as per patient's tolerance. Immediate post-op XRays were done routine A-P and scapular view to assess the reduction of fracture and stability of fixation.

If the bone was severely osteoporotic and fixation was less than rigid, motion was delayed, otherwise redisplacement of the fracture fragments could have occurred. Shoulder wheel exercises were permitted by the second or third week and gentle passive forward flexion and internal and external rotation exercises by the third or fourth week. By the fourth to sixth week, active exercises were started. Patients were discharged with arm pouch and advise to continue pendulum exercises. Patients underwent rehabilitation as per protocol.

Patients were followed from 4 weeks to 1 year on OPD basis at intervals of 4 weeks, 8 weeks, 12 weeks, 16 weeks, 20 weeks, 6 Months and 1 Year. During this period in each visit clinical evaluation of wound healing, pain, shoulder function and range of movements were assessed and recorded. Clinically fracture was consider united when there was no tenderness at the fracture site and full shoulder function is present. Radiologically fracture was regarded as united when there is no visible fracture line.

Results were evaluated by the use of Neer's shoulder score based on pain, function, range of motion and anatomy for each case assessed and recorded.

\section{Observations and results}

All the cases of open reduction and internal fixation were approached by delto pectoral approach. Fractures was anatomically reduced and fixed with locking compression plate (PHILOS) with $3.5 \mathrm{~mm}$ locking screws and $4.5 \mathrm{~mm}$ cortical screws for 14 patients. Four patients underwent hemiarthroplasty with Neer's prosthesis. Twelve patients underwent K-Wire fixation. Fixation rigidity was checked on 
table. Patients were immobilized in the arm pouch, all patients were encouraged pendulum exercises in the second week. Sutures were removed on the 12 th post-operative day.

4.1 Age incidence: In our series of thirty patients, nine were in the age group of $21-40(30 \%)$, twelve in the age group of $41-60(40 \%)$, nine in the age group of greater than $60(30 \%)$.

4.2 Sex incidence: Eighteen out of thirty patients were males $(60 \%)$ and twelve $(40 \%)$ were females.

4.3 Mode of injury: The most common mode of injury observed in our series was road traffic accident (RTA). It accounted for twenty $(66.7 \%)$ out of t-irty patients. The next common cause was history of fall accounting for nine $(30 \%)$ out of thirty patients and one patient (3.3\%) had history of assault.

4.4 Type of fracture: The common type of fractures observed in our series were two part fracture accounting for twelve $(40 \%)$ out of thirty patients, along with three-part fracture accounting for eleven of thirty patients (40\%). Four-part fractures were seen in total of seven patients $(23.3 \%)$ including four patients having 4 part fracture dislocations.

4.5 Mode of internal fixation: In our study, fourteen patients $(46.7 \%)$ were treated by open reduction and internal fixation with Locking compression plate (PHILOS plate), eight patients $(26.7 \%)$ were treated by Percutaneous $\mathrm{K}$ wire fixation, four patients $(13.3 \%)$ were treated by open reduction and fixation with $\mathrm{k}$-wires and four patients (13.3\%) were treated by shoulder hemiarthroplasty.

The average follow up duration was 11.4 months. Range- (912 months). The average time taken for clinical union was 11.5 weeks (8-16weeks) and for radiological union 17.3 weeks ( 16 to 24 weeks).

\subsection{Complications}

During the follow up period six patients had post-operative infection $(20 \%)$, ten patients had shoulder stiffness $(33.3 \%)$, one patient $(3.3 \%)$ had implant loosening, one patient had malunion. There were no incidences of non-union or osteonecrosis of the proximal humerus.

Table 1: Distribution of Complications of patients studied

\begin{tabular}{|c|c|c|}
\hline Complications & Number of patients & $\%$ \\
\hline Nil & 12 & 40.0 \\
\hline Present & 18 & 60.0 \\
\hline - $\quad$ Post-op Infection & 6 & 20.0 \\
\hline - $\quad$ Stiffness & 10 & 33.3 \\
\hline - $\quad$ Malunion & 1 & 3.3 \\
\hline - $\quad$ Implant loosening & 1 & 3.3 \\
\hline - $\quad$ Non union & 0 & 0.0 \\
\hline - $\quad$ osteonecrosis & 0 & 0.0 \\
\hline
\end{tabular}

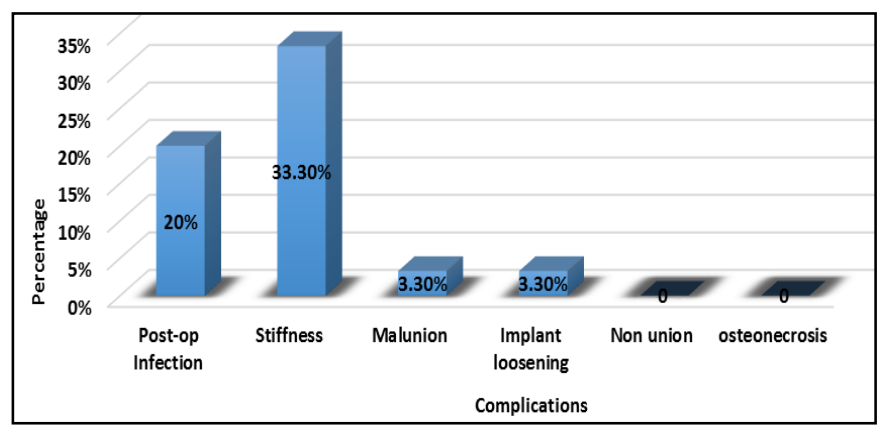

Fig: Complications
Table 2: Average of range of motion of patients treated

\begin{tabular}{|c|c|c|}
\hline Motion & Maximum ROM & Observed ROM \\
\hline Abduction & $180^{\circ}$ & $120^{\circ}$ \\
\hline Forward Flexion & $180^{\circ}$ & $130^{\circ}$ \\
\hline Extension & $45^{\circ}$ & $35^{\circ}$ \\
\hline External Rotation & $60^{\circ}$ & $30^{\circ}$ \\
\hline Internal Rotation & $90^{\circ}$ & $60^{\circ}$ \\
\hline
\end{tabular}

Table 3: Average of score of pain, function, ROM and Anatomy of patients by different treatment modalities

\begin{tabular}{|c|c|}
\hline Treatment Modalities & Average Score \\
\hline ORIF with PHILOS & 82.93 \\
\hline ORIF with K-Wire & 75.75 \\
\hline CRIF with K-Wire & 86.37 \\
\hline Hemiarthroplasty & 82.75 \\
\hline
\end{tabular}

Table 4: Average of score of pain, function, ROM and Anatomy of patients treated by all modalities

\begin{tabular}{|c|c|c|}
\hline Modalities & Min-Max & Mean \\
\hline Pain & $30-35$ & 33.32 \\
\hline Function & $16-30$ & 24.78 \\
\hline ROM & $12-19$ & 15.72 \\
\hline Anatomy & $4-10$ & 8.13 \\
\hline Total & $62-94$ & $\mathbf{8 1 . 9 5}$ \\
\hline
\end{tabular}

The mean scores observed on Neer's score was pain (33.32units), function (24.78units), range of motion (15.72units), anatomy (8.13units) and the total Neer's score was 81.95 .

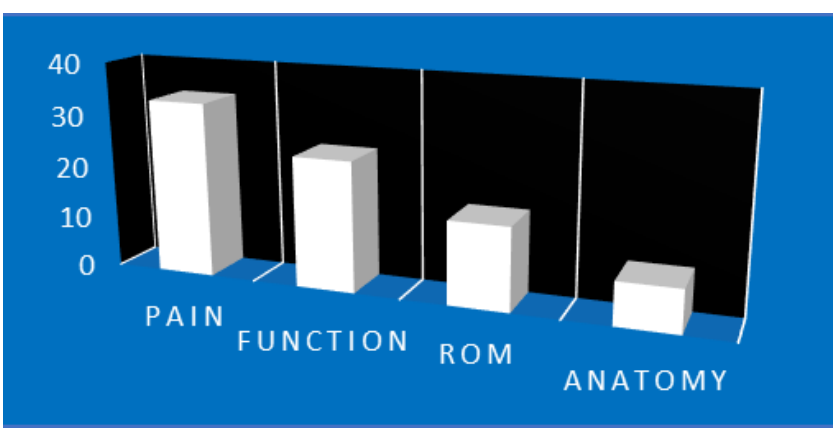

Fig: Average score

\subsection{Results}

Fourteen patients were treated by ORIF with plate (PHILOS). Two had excellent results and two had satisfactory results for two part fracture. For three part fracture, two had excellent and six had satisfactory result. For four part fracture, one had satisfactory result and one had failure.

Twelve patients were treated by open/closed reduction with $\mathrm{K}$-wires. Percutaneous K-wire fixation was done in case of 2 part fractures and open reduction was done in case of 3 part and 4 part fractures not amenable to closed reduction. Also tension band wiring was done whenever required. For CRIF with $\mathrm{K}$-wire done in case of 2 part fracture, 3 had excellent results, 4 had satisfactory results and 1 had unsatisfactory result. For ORIF with K-wire done in case of 3 part 2 had satisfactory results and 1 had failure. For 4 part treated by ORIF with K-wire one had failure.

Hemiarthroplasty with NEER's prosthesis was done in case of 4 part fractures. Three had satisfactory results and one had unsatisfactory result.

\section{Overall results}

Of the thirty patients, $7(23.3 \%)$ had excellent results, 17 
$(56.7 \%)$ had satisfactory results, $4(13.3 \%)$ had unsatisfactory results and $2(6.67 \%)$ were failure.

Table 4: Distribution of overall results of patients studied

\begin{tabular}{|c|c|c|}
\hline Results & Number of patients & $\mathbf{\%}$ \\
\hline Excellent & 7 & $23.3 \%$ \\
\hline Satisfactory & 17 & $56.7 \%$ \\
\hline Unsatisfactory & 4 & $13.3 \%$ \\
\hline Failure & 2 & $6.67 \%$ \\
\hline Total & 30 & $100.0 \%$ \\
\hline
\end{tabular}

Of the thirty patients, $7(23.3 \%)$ had excellent results, 17 $(56.7 \%)$ had satisfactory results, $4(13.3 \%)$ had unsatisfactory results and $2(6.67 \%)$ were failure.

Table 5: Distribution of overall results of patients studied

\begin{tabular}{|c|c|c|}
\hline Results & Number of patients & \% \\
\hline Excellent & 7 & $23.3 \%$ \\
\hline Satisfactory & 17 & $56.7 \%$ \\
\hline Unsatisfactory & 4 & $13.3 \%$ \\
\hline Failure & 2 & $6.67 \%$ \\
\hline Total & 30 & $100.0 \%$ \\
\hline
\end{tabular}

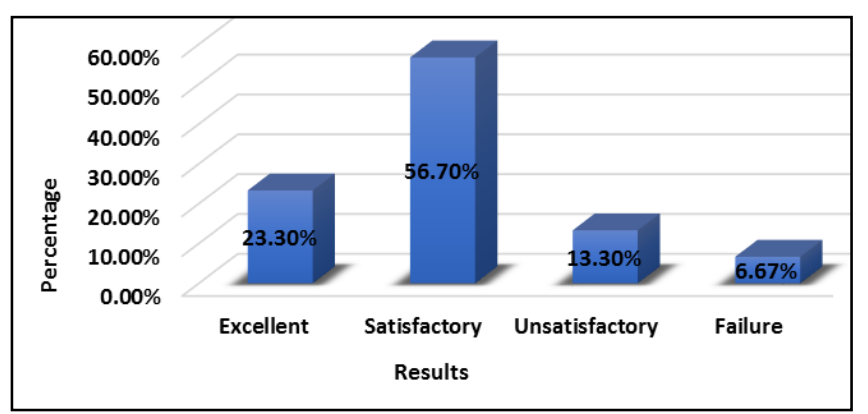

Fig: Results

\section{[A] Cases of or $\&$ if With Philos Plate}
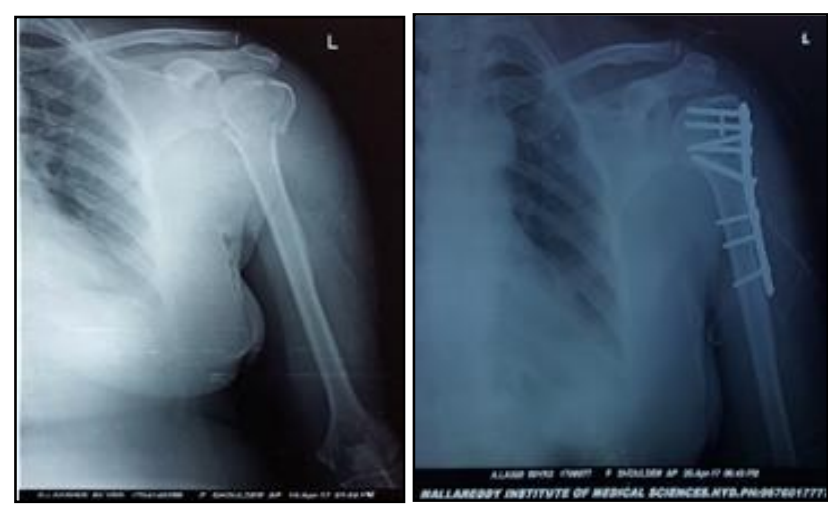

Pre op and post op $x$-ray: three part fracture

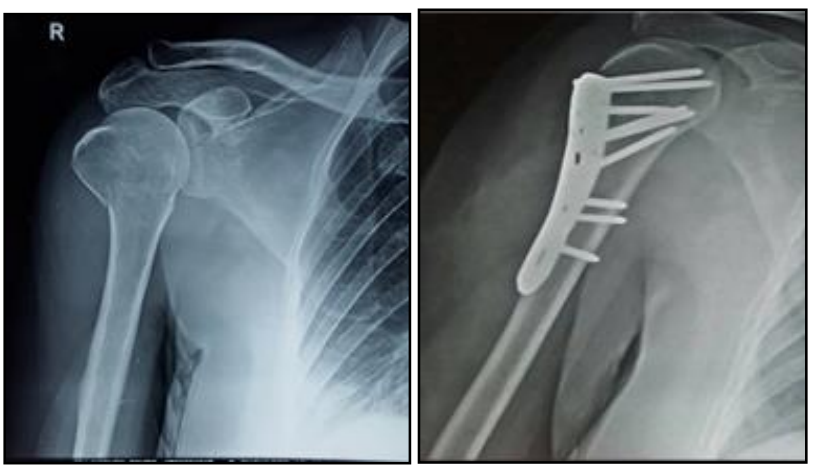

Pre op and post op x-ray: two part fracture

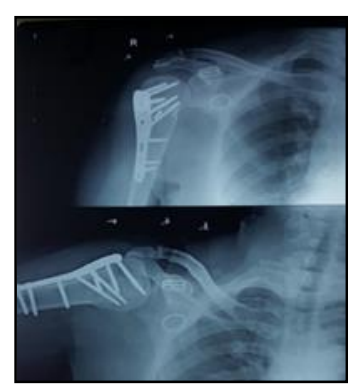

Follow up x-ray at at 1 year revealing fracture union

Range of motion at 16 weeks follow up in a case of Orif with Philos plate
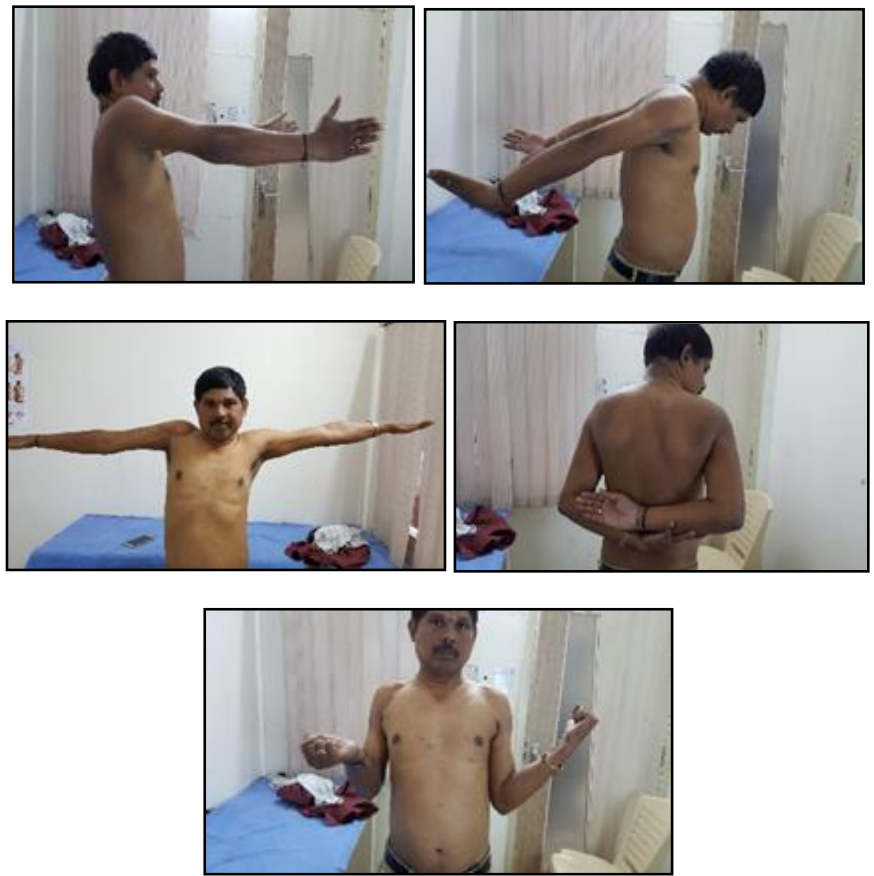

[B] Case of Crif with k-wire

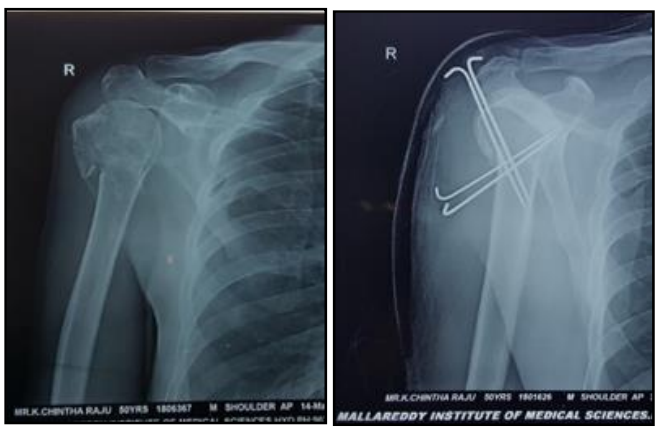

Pre op and post op x-ray of 2 part fracture

[C] Case of Orif with k-wire

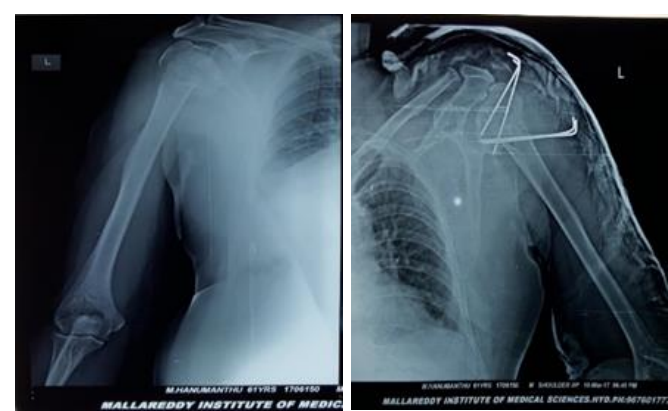

Pre op and post op x-ray of 3 part fracture 
Range of motion at 16 weeks follow up in a case of crif with k-wire
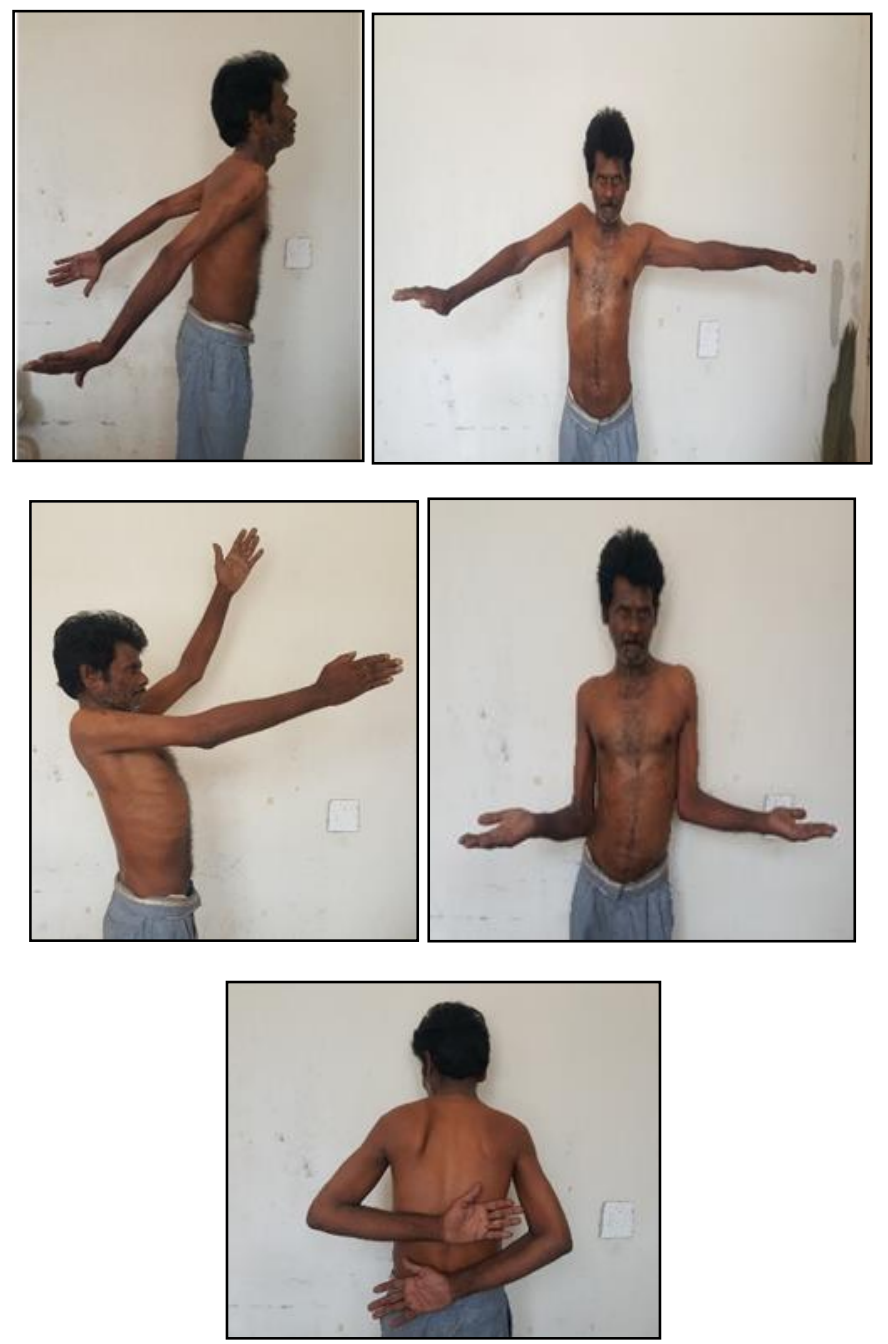

[D] Cases of hemiarthroplasty
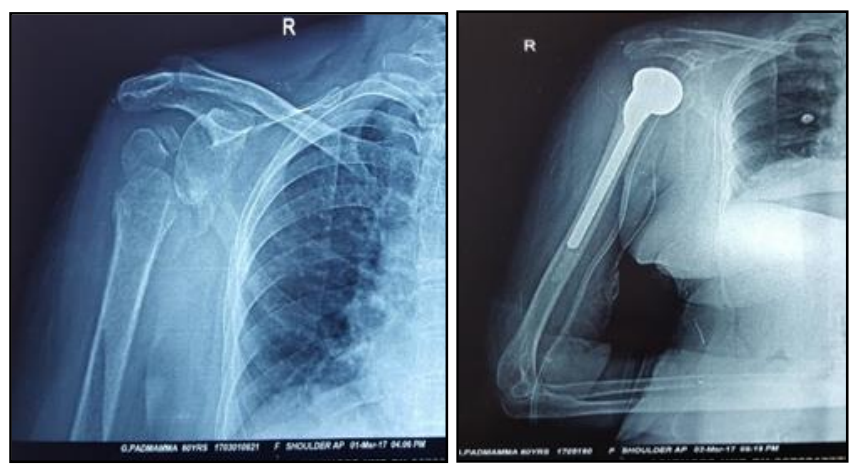

Pre-op and post-op x-ray: Four part fracture

Range of motion at 16 weeks follow up in a case of shoulder hemiarthroplasty
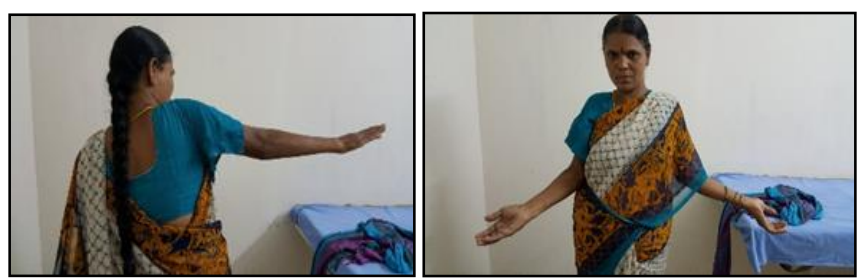
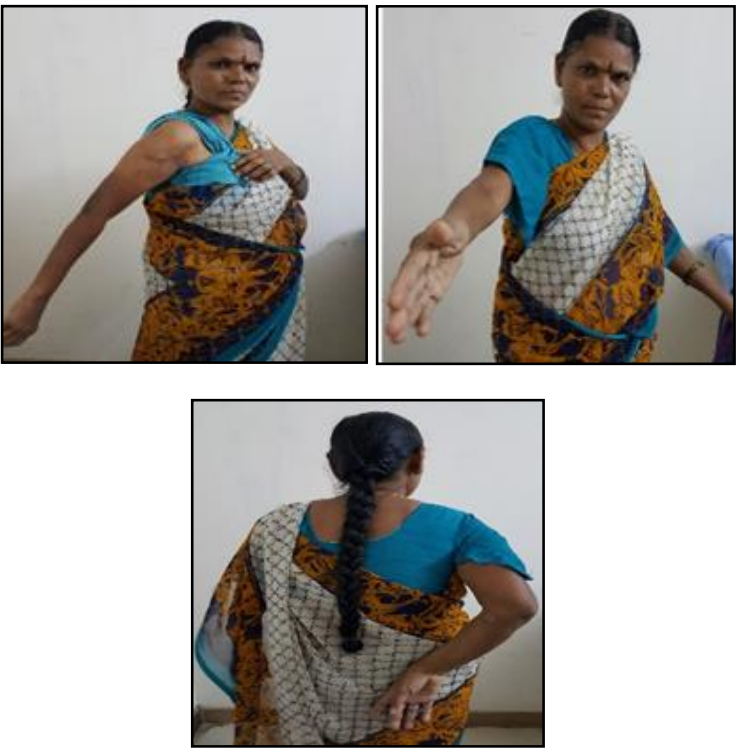

\section{Discussion}

Proximal humeral fractures account for almost 4 to $5 \%$ of all fractures. These fractures have a dual age distribution occurring either in young people following high energy trauma or in those older than 50 years with low velocity injuries like simple fall.

Earlier these fractures were considered simple and were managed by plaster cast technique, slings and slabs, but recent advances in understanding of anatomy, good surgical skills and better instrumentation has led to various modalities for the treatment of these fractures like percutaneous pinning, plate fixation or prosthetic replacement.

Due to awareness of its complexity and complications, these fractures have stimulated a growing interest in finding the optimal treatment. Most of the proximal humeral fractures are non-displaced or minimally displaced and stable. These can be treated non-operatively successfully with early rehabilitation. But severely displaced and comminuted fractures warrant surgical management for optimum shoulder function.

In our institution we managed 30 patients with fractures of proximal humerus by open/closed reduction and internal fixation. Twelve patients were treated with ORIF/CRIF $\mathrm{K}$ wires, 14 were treated by ORIF with locking compression plate and 4 underwent hemiarthroplasty.

\subsection{Age Incidence}

The average age incidence in our series of 30 patients analyzed, ranging between 18 to 70 years, was 50.5 years, which was consistent with the age incidence in studies done by Neer ${ }^{[10,11]}(55.3$ yrs). In a study by Dolfi Herscovici et al ${ }^{[12]}$, the average age was 52 year. Court-Brown et al. [2] reported in their epidemiological study with an average age of 66 years, for men being 56 years and for women 70 years. Chandan Kumar et al. ${ }^{[13]}$ reported average age to be 57.8 years. In our series 16 out of 30 patients were below or equal to 50 years, average age for men was 45.4 yrs and for female was 58 yrs.

\subsection{Sex incidence}

Regarding sex incidence study of literature reveals predominance of proximal humeral fractures (PHF) in females in an elderly age group ${ }^{2}$ and in young males due to high energy trauma like RTA. The male:female ratios are 1:0.8 in Dolfi Herscovici ${ }^{[12]}$ study, 1:1.3 in Ko Jy,Yamamoto 
${ }^{[14]}$ study, 1:2.7 in a study by Court- Brown et al. ${ }^{[2]}$ and 1:0.6 in a study by Chandan Kumar et al ${ }^{[13]}$. In our series the male to female ratio is $1: 0.7,12$ among 30 patients were females. Our study shows that most of the males are young suffering high energy trauma as a result of RTA. In females, most proximal humerus fracture are osteoporotic fractures in women over the age of 50 years.

\subsection{Mode of injury}

The mode of injury commonly observed in our series were road traffic accidents (RTA) accounting for 18 patients $(60 \%), 11(36.7 \%)$ patients had history of fall from height and $01(3.3 \%)$ had a history of assault. Thus showing high velocity injury as a major cause. A study by Dolfi Herscovici [12] revealed $19(47.5 \%)$ road traffic accidents, $20(50 \%)$ history of fall and $01(2.5 \%)$ history of assault out of the 40 cases studied. In another study by Ko Jy Yamamoto ${ }^{[14]}$, 12(75\%) had road traffic accident and $04(25 \%)$ had history of fall in a series of 16 cases studied. Comparing our study with the published series, we find that the emergence of high velocity injury due to road traffic accidents has been a major cause of these fractures.

\subsection{Type of fracture}

The study of type of fracture in our series revealed $12(40 \%)$ were 2 part fractures, $11(36.7 \%)$ were 3 part fractures and 07 $(23.3 \%)$ were 4 part fractures. In study done by Dolfi Herscovici ${ }^{[12]}, 20(50 \%)$ were 2 part fractures, 16(40\%) were 3 part fractures and $4(10 \%)$ were 4 part fractures indicating that the incidence of type of fracture is nearly consistent with the studies in literature. Chandan Kumar et al. ${ }^{[13]}$ reported 11 $(21.15 \%)$ to be 2 part fractures, $22(42.3 \%)$ to be 3 part fractures and $19(36.5 \%)$ to be 4 part fractures.

In two part surgical neck fractures, the head was in the neutral position as both the tuberosities were attached to it, and the shaft was pulled medially due to the pull of the pectoralis major. Traction, with flexion and some adduction was required to reduce the fracture. In the case where reduction was not possible, there was found to be soft tissue interposition which was blocking reduction, open reduction was then performed ${ }^{[15,16]}$.

Displaced two part greater tuberosity fractures were usually found retracted posteriorly and superiorly. Closed reduction was performed under $\mathrm{C}$-arm supervision and fixed with $\mathrm{K}$ wires.

Displaced three part fractures were difficult to reduce and still more difficult to hold reduced (unstable Fracture), probably because if the greater tuberosity was attached to the head, it was pulled into external rotation with the humeral articular surface facing forward. If lesser tuberosity was attached to it, the articular surface was facing posteriorly. The shaft was pulled medially by the pectoralis major and probably the long head of biceps was caught between the fracture fragment and prevented reduction. Moreover, since the fracture usually occurred in osteoporotic bone, vigorous manipulation and repeated attempts at reduction could cause further comminution at the fracture site. These fractures were treated by open reduction.

The similar finding has been found in literature published by various authors $[15,16,17]$

\subsection{Modes of internal fixation}

Various modes of internal fixation were employed in our series of 30 patients. Fourteen (35\%) underwent open reduction and internal fixation with PHILOS plate, twelve
(40\%) underwent fixation with K-wires, 06 (5\%) underwent prosthetic replacement. In study done by Neer [10, 11], 43 $(36.8 \%)$ patients underwent open reduction and internal fixation with plate, $43(36.8 \%)$ of 4 part fractures and selected 3 part fractures underwent prosthetic replacement. In another series by R.J. Hawkins ${ }^{[18]}, 15$ patients 14 (93.3\%) underwent internal fixation with $\mathrm{K}$-wires/cancellous screws and only one underwent fixation with AO buttress plate. Gerber C et al. ${ }^{[19]}$ in his study of 34 fractures, 8 were treated by ORIF with plate, 9 with $\mathrm{K}$-wire fixation and the rest by osteosutures and screw fixation.

Many authors in their published literature have mentioned that, in management of displaced proximal humerus, good reduction is mandatory and stable fixation gave good results. They also reported that open reduction and internal fixation in young adults gives better outcome. In older persons the quality of bone and soft tissue disruption should be given importance, and percutaneous fixation gives good results. ${ }^{[15}$, $19,16,17]$.

\subsection{Complications}

In our series $10(33.3 \%)$ had shoulder stiffness and $06(20 \%)$ had postoperative infection, $1(3.3 \%)$ had malunion and 1 $(3.3 \%)$ had implant loosening. Compared to other series $[10,11$, ${ }^{18]}$, we had stiffness in $33.3 \%$ of patients, most of these patients were elderly who were unwilling or uncooperative to undergo rigorous rehabilitation programme. Out of six patients $(20 \%)$ who had postoperative infection, 03 of them treated by open reduction had superficial infection which subsided with systemic antibiotics, 02 patient had pin tract infection, which subsided after removal of ' $\mathrm{K}$ ' wires, but 01 patient treated by ORIF with K-wires had deep seated infection and K-wires loosening, for which debridement and systemic antibiotic was given and infection got under control, but later went into failure outcome. In 10 patients treated by different modalities who developed stiffness, phase wise physiotherapy was started after clinical union was confirmed. Four patients had unsatisfactory results and the others ended up with satisfactory result. One patient treated by ORIF with PHILOS plate developed malunion due to inadequate anatomical reduction resulting in failure outcome due to severe restriction of movements. The complications in other series like study done by Neer ${ }^{[19]}$ of 117 patients, 03 had postoperative infection, 04 had malunion, 07 had non-union and 08 had avascular necrosis of the humeral head. In another series by Richard J Hawkins ${ }^{[18]}$ of 15 patients, 02 had implant loosening and 02 had avascular necrosis of the humeral head.

Table 6: Complication Related Study Pattern

\begin{tabular}{|c|c|c|c|}
\hline & Neer's $^{[\mathbf{1 0}, \mathbf{1 1}]}$ & Richard J Hawkins $^{[\mathbf{1 8}]}$ & Present Study \\
\hline Stiffness & 00 & 00 & $10(33.3 \%)$ \\
\hline Post op infection & $03(2.5 \%)$ & 00 & $06(20 \%)$ \\
\hline Implant loosening & 00 & $02(13.3 \%)$ & $01(3.3 \%)$ \\
\hline Malunion & $04(3.4 \%)$ & 00 & $01(3.3 \%)$ \\
\hline Nonunion & $07(6 \%)$ & 00 & 00 \\
\hline Osteonecrosis & $08(6.8 \%)$ & $02(13.3 \%)$ & 00 \\
\hline
\end{tabular}

\subsection{Follow Up}

All fractures were united in the follow-up. The mean follow up period was 11.4 months during which evaluation for clinical union, radiological union and functional assessment were done. All fractures revealed clinical union at an average of 11.5 weeks (8-16weeks). Radiological union was noticed at an average of 17.3 weeks (16-24 weeks). Literature reveals that the average clinical union time for minimally invasive procedure is about 8-10 weeks and for ORIF with plates is 
about 12-14 weeks ${ }^{[12,14,18]}$.

\subsection{Range of motion}

Range of motion at the end of full follow up period was assessed regarding the movements of abduction, forward flexion, internal rotation, external rotation and extension. In our series the average values for the above shoulder movements were abduction $120^{\circ}$, forward flexion $130^{\circ}$, Internal rotation $60^{\circ}$, external rotation $30^{\circ}$ and extension $35^{\circ}$.The results were satisfactory when compared to other study series ${ }^{[14,18]}$.

\subsection{Discussion of results obtained with different modalities of fixations}

Our study was conducted in Malla Reddy Institute Of medical Sciences, Hyderabad. The cases with proximal humerus fracture were initially examined in outpatient department or casualty.

Different studies, which have used the Neer's scoring system for assessment of results, demonstrate a fairly similar pattern of results with $70-80 \%$ patients having satisfactory to excellent results and $20-30 \%$ having un-satisfactory to failure results. In our series, 14 cases of two part, three part and four part fractures were treated by open reduction and internal fixation with locking plate, $4(28.6 \%)$ had excellent results, $8(57.14 \%)$ had satisfactory results, one patient (7.14\%) had unsatisfactory results and one (7.14\%)was a failure. When compared with other studies in case of Neer's, $(63.3 \%)$ had excellent and satisfactory results and $36.7 \%$ had faiure ${ }^{[10,11]}$. Lungershausen $\mathrm{W}$ et $a l^{20}$ in his 51 patients treated with locking plates showed $70.8 \%$ of patients followed-up presented with an excellent or good result according to Neer's criteria. In study by Chandan Kumar et al ${ }^{[13]}, 66 \%$ of the patients treated by locking plate fixation had excellent to good outcome in constant scoring system. The overall mean Constant score was $72.34 \pm 13.57$ which signifies 'good' outcome. Thyagarajan et al. ${ }^{[21]}$ in their study on 30 patients treated by PHILOS showed an overall average Constant score of 57.5 which shows 'moderate outcome'. The mean age in this series was 58 years (range 19-92 years) and fractures were Neer's 2-part, 3-part, and 4-part fractures. They concluded that the locking plate provides good fracture stability and allows early mobilization of the shoulder without compromising fracture union. This implies that our results with OR\& IF with plate almost correlated with the studies in literature.

In our study, open reduction and K-wire fixation was done in four cases of 3 part and 4 part fractures where the bone is highly osteoporotic and closed reduction was not possible. We got satisfactory result in $2(50 \%)$, unsatisfactory result in $1(25 \%)$ and $1(25 \%)$ failure. Failure was due to infection and inadequate fixation. A study by Darder A et al ${ }^{[22]}$ in his study of 4 part fractures treated by ORIF with K-wires, showed results were excellent and satisfactory in $63.63 \%$, unsatisfactory in $30.3 \%$ and failure in $6 \%$. He suggested that prosthetic replacement should be considered as primary treatment in cases with marked comminution of the humeral head, in fracture-dislocations and in old age. In another study of 3 part fracture by Hawkins et al. ${ }^{[20]}, 93.3 \%$ had excellent and satisfactory results all of them had underwent OR \& IF with $\mathrm{K}$ wires/cancellous screws and one failure in this series was fixation with AO buttress plate.

Studies reveal that results of percutaneous pinning provides good results regarding functional outcome. Jaberg et al. ${ }^{[23]}$ in his study showed $91.6 \%$ of the cases had excellent $(70.8 \%)$ and satisfactory $(20.8 \%)$ results with $04(8.3 \%)$ failures. In our series, 8 patients with 2 part displaced fracture underwent percutaneous pinning, three $(37.5 \%)$ had excellent results, four $(50 \%)$ had satisfactory results and one(12.5\%) had unsatisfactory result.

Results pertaining to prosthetic replacement were studied. Studies reveal that prosthetic replacement may be the treatment of choice in some 4 part fractures and selected 3 part fractures in the elderly. Neer's study shows $11.6 \%$ had excellent results, $79 \%$ had satisfactory results, $4.7 \%$ had unsatisfactory and $4.7 \%$ had failure. In another study by Catherine A compito ${ }^{[24]}, 44.3 \%$ had excellent results, $31.4 \%$ had satisfactory results and $24.3 \%$ had unsatisfactory results. In our series of 30 patients, 04 underwent prosthetic replacement for four part fracture with dislocation out of which $03(75 \%)$ showed satisfactory result and $01(25 \%)$ had unsatisfactory result. The unsatisfactory result was due to poor rehabilitation and unwillingness for physiotherapy.

Overall results analyzed in our series shows $80 \%$ of the patients had excellent and satisfactory results and $20 \%$ had unsatisfactory and failure outcome. This was observed to be on par with the studies in literatures ${ }^{[18,24,14,12]}$. The results confirm that the operative treatment of the proximal humerus fracture gives good results, if anatomical or near anatomical reduction is obtained. If the bone quality, as judged by the thickness of the cortex of the proximal humeral diaphysis is good, anatomical reduction can be obtained and maintained in approximately $90 \%$ of cases ${ }^{[19]}$.

Table 7: Overall Results

\begin{tabular}{|c|c|c|c|c|}
\hline & Excellent & Satisfactory & Unsatisfactory & Failure \\
\hline Neer's Study $^{[11]}$ & $15(17.4 \%)$ & $43(50 \%)$ & $02(2.3 \%)$ & $26(30 \%)$ \\
\hline R.J. Hawkins ${ }^{[18]}$ & $08(53.3 \%)$ & $06(40 \%)$ & 00 & $01(6.7 \%)$ \\
\hline Present Study & $07(23.3 \%)$ & $17(56.7 \%)$ & $04(13.3)$ & $02(6.67)$ \\
\hline
\end{tabular}

The unsatisfactory results in our series was seen mostly in elderly patients who were reluctant or not cooperative for rigorous rehabilitation programme. Decreased immunity status lead to infection in few of these patients resulting in unsatisfactory and failure outcome.

\section{Conclusion}

The principles of fixation of proximal humerus fractures are reconstruction of the articular surface, including the restoration of the anatomy, stable fixation, with minimal injury to the soft tissues preserving the vascular supply.Bimodal age incidence is seen with peak incidences between 20-40 years and another between 50 -70 years. In younger patients, proximal humeral fractures usually are caused by high-energy trauma like RTA. In older patients with osteoporosis, even less severe trauma like fall from height can produce significant injury. Closed reduction and percutaneous pinning can be used for un-displaced or displaced fractures of the proximal humerus without comminution, in the younger age groups with good bone quality. In older individuals it is good to fix with percutaneous $\mathrm{K}$ wires, considering the quality of bone (osteoporosis) and also to reduce the period of surgery. Although closed reduction and percutaneous $\mathrm{K}$-wire fixation is a technically demanding procedure, it offered excellent results in our patients for the treatment of unstable 2 part proximal humerus fractures. Patients who have metaphyseal comminution and patients who have a three-part fracture with displacement of the greater tuberosity, open reduction, limited 
dissection and internal fixation should be performed. Proximal humerus locking plate (PHILOS) gives reliable fixation for 2-part and 3-part fractures and has good functional outcome. In more complicated fracture patterns of 4-part fractures, its use is associated with poor clinical outcome. Prosthetic replacement should be considered as primary treatment in cases with marked comminution of the humeral head, in fracture-dislocations, and in elderly patients. Primary hemiarthroplasty remains a good option, especially when treating elderly patients. Rehabilitation plays a key role. After the fracture is stabilized, active movements of the shoulder should be started and physiotheraphy should be advised post discharge.

\section{References}

1. Wong KL, Williams Jr GR. Proximal Humeral Fractures:Diagnosis and Management. UPOJ. Spring. 1998; 11:1-11.

2. Court-Brown CM, Garg A, McQueen MM. The epidemiology of proximal humeral fractures. Acta orthopaedica Scandinavica. 2001; 72(4):365-71.

3. Lobo MJ, Levine WN. Classification and closed treatment of proximal humerus fractures. In Wirth MA, editor. Proximal humerus fractures. Chicago: American Academy of Orthopaedic Surgeons, 2005, 1-13.

4. Hartmann A, Resch H. Treatment of proximal humerus fractures. In Galatz L, editor. Orthopaedic knowledge update shoulder and elbow 3. Rosemont: American Academy of Orthopaedic Surgeons, 2008, 405-22.

5. Green A, Norris T. Proximal humerus fractures and fracture-dislocations. In Jupiter J, editor. Skeletal trauma. 3rd ed. Philadelphia: Saunders, 2003, 1532-624.

6. Robinson CM. Proximal humerus fractures. In: Bucholz RW, Court-Brown CM, Heckman JD, Tornetta P, editors. Fractures in adults. Philadelphia: Lippincott Williams \& Wilkins, 2010, 1039-105.

7. Huopio J, Kroger H, Honkanen R, Saarikoski S, Alahava E. Risk factors for perimenopausal fractures: a prospective study. Osteoporos Int. 2000; 11:219-27.

8. Kamal I. Bohsali, Aaron J. Bois, Michael A. Wirth. Fractures of the Proximal Humerus. In Rockwood Jr CA, Matsen III FA, editors. The Shoulder. 5th ed.: Elsevier, 2017, 183-242.

9. Zyto K, Kronberg M, Broström LÅ. Shoulder function after displaced fractures of the proximal humerus. Journal of shoulder and elbow surgery. 1995; 4(5):331-6.

10. Neer CS. Displaced proximal humeral fractures: Part I. Classification and evaluation. The Journal of Bone \& Joint Surgery. 1970; 52(6):1077-89.

11. Neer CS. Displaced proximal humeral fractures: Part II. Treatment of three-part and four-part displacement. JBJS. 1970; 52(6):1090-103.

12. Herscovici Jr D, Saunders DT, Johnson MP, Sanders R, DiPasquale T. Percutaneous fixation of proximal humeral fractures. Clinical Orthopaedics and Related Research ${ }^{\circledR}$. 2000; 375:97-104.

13. Kumar C, Gupta AK, Nath R, Ahmad J. Open reduction and locking plate fixation of displaced proximal humerus fractures. Indian journal of orthopaedics. 2013; 47(2):156.

14. Ko JY, Yamamoto R. Surgical treatment of complex fracture of the proximal humerus. Clinical Orthopaedics and Related Research®. 1996; 327:225-37.

15. Pritsch M, Greental A, Horoszowski H. Closed pinning for humeral fractures. The Journal of Bone and Joint
Surgery-british Volume. 1997; 79(3S):337.

16. Resch H, Povacz P, Fröhlich R, Wambacher MA. Percutaneous fixation of three-and four-part fractures of the proximal humerus. J Bone Joint Surg Br. 1997; 79(2):295-300.

17. Kyle RF. Current Techniques In Proximal Humeral Fractures. The Journal of Bone and Joint Surgery-british. 1997; 79(4S):403.

18. Hawkins RJ, Bell RH, Gurr K. The three-part fracture of the proximal part of the humerus. Operative treatment. The Journal of bone and joint surgery. American. 1986; 68(9):1410-4.

19. Gerber C, Werner CM, Vienne P. Internal fixation of complex fractures of the proximal humerus. Bone \& Joint Journal. 2004; 86(6):848-55.

20. Lungershausen W, Bach O, Lorenz CO. Locking plate osteosynthesis for fractures of the proximal humerus. Zentralblatt fur Chirurgie. 2003; 128(1):28-33.

21. Thyagarajan DS, Haridas SJ, Jones D, Dent C, Evans R, Williams R. Functional outcome following proximal humeral interlocking system plating for displaced proximal humeral fractures. International journal of shoulder surgery. 2009; 3(3):57.

22. Darder A, Darder JA, Sanchis V, Gastaldi E, Gomar F. Four-part displaced proximal humeral fractures: operative treatment using Kirschner wires and a tension band. Journal of orthopaedic trauma. 1993; 7(6):497-505.

23. Jaberg H, Warner JJ, Jakob RP. Percutaneous stabilization of unstable fractures of the humerus. The Journal of bone and joint surgery. American volume. 1992; 74(4):508-15.

24. Compito CA, Self EB, Bigliani LU. Arthroplasty and acute shoulder trauma. Reasons for success and failure. Clinical orthopaedics and related research. 1994; (307):27-36. 